\title{
SUJETOS EJEMPLARES PARA UNA POLÍTICA ESPIRITUAL. NOTAS SOBRE ALGUNOS DISCURSOS DE JOAQUÍN V. GONZÁLEZ
}

\author{
EXEMPLARY SUBJECTS FOR A SPIRITUAL POLITICS. \\ SOME NOTES ON JOAQUÍN V. GONZÁLEZ' S SPEECHES
}

\author{
Cristina Beatriz Fernández \\ Universidad Nacional de Mar del Plata (UNMDP). Mar del Plata, Argentina \\ Consejo Nacional de Investigaciones Científicas y Técnicas (CONICET), Argentina. \\ crisfer@mdp.edu.ar
}

Resumen: El objetivo del presente trabajo es analizar algunos discursos incluidos en el libro Política espiritual de Joaquín V. González, escritos entre 1905 y 1909. Especialmente, se estudian aquellos centrados en el elogio u homenaje a personalidades del mundo académico o cultural, a partir de lo cual se esbozan algunas conclusiones respecto de la funcionalidad de estas piezas oratorias en relación con el proyecto político y educacional de González.

Palabras clave: Educación, sujetos modernos, etopeya.

\begin{abstract}
The aim of this paper is to analyse some spechees published in the book Política espiritual, which were addressed by Joaquín V. González between 1905 and 1909. We selected those discourses devoted to eulogise or to honour outstanding people at the academic or cultural world. Finally, we propose some conclusions on the function of these oratorical pieces in relation with the political and educational project of Joaquín González.
\end{abstract}

Keywords: Education, modern subjects, etopeya.

Recibido: 06.08.2014. Aceptado: 10.03.2015.

$\mathrm{U}$ NA DE LAS FIGURAS centrales del universo cultural en la Argentina del entresiglos XIX-XX fue Joaquín Víctor González, jurista, político, 
educador y escritor consagrado por ensayos como La tradición nacional (1888) y El juicio del siglo, o cien años de historia argentina (1910), así como por los relatos de tenor autobiográfico de Mis montañas (1893). La figura de González es, en muchos sentidos, emblemática del hombre de letras tal como se concebía con anterioridad a la especialización y profesionalización que, aunque no logradas enteramente, serían uno de los objetivos del proyecto escriturario de los modernistas.

Nacido en la provincia de La Rioja en 1863 y formado en las aulas de la Universidad de Córdoba, se destacó tempranamente por su actuación política, a la que accedió por pertenecer a una de las familias tradicionales de su provincia, ligada a los intereses del Partido Autonomista Nacional. Por ello fue un joven gobernador de su provincia, desde 1889 a 1891, así como parlamentario en varias oportunidades, hasta el mismo momento de su muerte, en Buenos Aires, en 1923. Su formación intelectual lo convirtió en uno de los más destacados personajes públicos en el marco del orden conservador que, a la sombra del liberalismo jurídico y económico, propició medidas de modernización social y secularización cultural en la Argentina, en un período signado por la actuación de la llamada generación del 80 . Fueron también las vinculaciones de su familia las que lo llevaron a la dirección de noticias del diario La Prensa, que en 1869 había sido fundado por José C. Paz en Buenos Aires.

González, quien en 1896 fue designado titular del Consejo Nacional de Educación y profesor de la Facultad de Filosofía y Letras de la Universidad de Buenos Aires, fue nombrado Ministro del Interior, de Justicia e Instrucción Pública en 1901, durante la presidencia de Julio Roca, cartera en la que continuó bajo la presidencia de Manuel Quintana, hasta 1906. La historiografía ha destacado el rol de Joaquín V. González como el ministro que, desde el roquismo, logró generar un espacio de interlocución entre el reformismo liberal y los intelectuales preocupados por la cuestión social, un tema no menor si se considera que el mismo proceso de modernización que había impulsado el estado roquista lo había llevado a una crisis social y cultural, con la aparición de nuevas demandas y nuevos actores (Dalmaroni, 2006: 59). Uno de los logros más trascendentes de González fue la fundación, sobre la base de una universidad provincial ya existente, de la 
actual Universidad Nacional de La Plata, en 1905, institución que presidió desde ese mismo año hasta $1918^{1}$.

Las reflexiones de González sobre la cultura argentina nutrieron la génesis del ensayo nacional y procuraron dar respuesta a la pregunta sobre la identidad nacional. Todavía bajo el influjo de la estética romántica y de autores como Lamartine y Chateaubriand, nuestro autor ofreció una interpretación de lo nacional que no excluía la mirada sobre el universo provinciano de la Argentina ni la revaloración del indio o del gaucho, en relativa disidencia con una parte de los pensadores liberales del siglo XIX argentino. Ya en estudios clásicos sobre su obra como los de Arturo Marasso (1946) y Fermín Estrella Gutiérrez (1969), se ha destacado la amplia cultura clásica y moderna del escritor riojano, su inclinación por las letras y la cultura anglosajona y su curiosidad por el pensamiento oriental, que llevarían a González a traducir los Cien poemas de Kabir a partir de la versión inglesa de Rabindranath Tagore ${ }^{2}$. Su valoración de los pintores primitivos italianos -una pasión que compartió con su admirado John Ruskin, temprano defensor de los prerrafaelitas ingleses- no iba reñida con la inevitable influencia del positivismo spenceriano, que lo llevaría a promover la ampliación de la educación científica en el currículum escolar.

Podría considerarse a González, como a Domingo F. Sarmiento o a José Ingenieros, como uno de los polígrafos que cifraron en sus textos, heterogéneos desde el punto de vista genérico, gran parte de la memoria cultural argentina. En un momento en que la literatura no había alcanzado la autonomía en tanto que práctica social, resulta operativo concebir los escritos de González como textos de cultura, en tanto que parte de un entramado semiótico que se expande, sincrónicamente, hacia el contexto de su propia producción y hacia el más amplio contexto cultural (Lotman, 1996).

${ }^{1}$ Una prueba clara del consenso logrado en torno de la figura intelectual y humana de Joaquín González la ofrece el hecho de que fue uno de sus adversarios políticos, el socialista Alfredo Palacios, quien desde su banca de senador promovió la iniciativa de editar las obras completas del ex-ministro de Roca, por cuenta del Estado.

${ }^{2}$ El influjo de la cultura anglosajona no se limitaba, en Joaquín González, a la literatura, sino también al pensamiento y la jurisprudencia ingleses y norteamericanos (Luna, 2001: 40). 
De allí la necesidad de explorar otras zonas de su producción, más allá de los célebres ensayos o relatos citados al principio de este trabajo, como los discursos producidos en el marco de su actuación pública. Parte de esos "Discursos académicos, sociales y parlamentarios", pronunciados entre 1905 y 1909, fueron reunidos en un libro dedicado "A la patria. 1810-1910" que, bajo el título de Política espiritual, fue publicado inicialmente en 1910, en Buenos Aires, por Lajouane y por la Librería Nacional. En la edición de las Obras completas del autor, ordenada por el Congreso de la Nación Argentina y publicada por la Universidad Nacional de La Plata, integra el volumen XV. Política espiritual está dividido en tres secciones: "En la tribuna académica", "Embajadores intelectuales" y "En la tribuna pública y parlamentaria"3. De los dieciocho discursos que reúne el volumen, varios de los cuales se relacionan con la labor de González al frente de la Universidad Nacional de La Plata o en la actividad política, nos interesa analizar aquí aquellos que configuran retratos de sujetos que, por algún motivo, son presentados como modélicos para el auditorio del escritor riojano en las distintas ocasiones en que fue convocado a la tribuna pública.

La sección del libro originada "En la tribuna académica" finaliza con el discurso titulado "La enseñanza argentina y los modelos de afuera", discurso que González brindó en nombre de la Asociación Nacional del Profesorado, en un homenaje al profesor español Rafael Altamira, el que tuvo lugar en la ciudad de Buenos Aires el 14 de octubre de 1909. Como es de esperar por el tema y la ocasión, el discurso se convierte en un elogio al ilustre visitante, cuyo valor intelectual se considera modélico y que funciona, a la vez, como una suerte de sinécdoque de la cultura española moderna. Así, se habla del "embajador académico de Oviedo y de la cultura española" (75), de un "apóstol impersonal de la ciencia y de la historia común [a América y España]" (76-77) y, sobre todo, de la encarnación de un modelo docente que las universidades argentinas del momento -Córdoba, Buenos Aires, Litoral, La Plata- estaban lejos de alcanzar: la del profesor universitario exclusivamente dedicado a las tareas docentes y de investigación, profesionalizado en esa rama de la actividad humana, lo que González llama "ese modelo para nosotros inaccesible del profesor completo" (84). Además de

${ }^{3}$ Todas las citas del texto corresponden a González 1935. Se indicará el número de página entre paréntesis. 
señalar a Altamira como un "modelo", tal como se aprecia en la cita precedente, nuestro autor lo equipara a Enrique Ferri, otro visitante ilustre de aquellos tiempos, porque son personalidades que representan la "cultura ambiente de sus países” (84). Demás está decir que Rafael Altamira, quien visitaba la Argentina en el marco de la gira americana que realizó entre 1909 y 1910 con motivo del tercer centenario de la Universidad de Oviedo, era una figura que resultaba ejemplar desde el punto de vista del proyecto educacional de Joaquín González, por su impronta krausista y su fuerte sentido moral.

La segunda parte del volumen, "Embajadores intelectuales", es la más significativa desde el punto de vista de la cuestión que nos interesa rastrear. Como el título de la sección lo indica, los discursos aquí compilados están centrados en el elogio a distintas personalidades, elogio que vincula, como en el caso de Altamira, el mérito individual y el carácter de representatividad de una entidad mayor - un país, una universidad, una disciplina- de la cual los sujetos cuyas cualidades se alaban son “embajadores”. Entre esos embajadores están los delegados de los Estados Unidos de Norteamérica, que visitaron la Argentina de paso hacia el Congreso Científico Panamericano de Santiago de Chile de 1908 y a los cuales Joaquín González les dirigió un discurso en su carácter de presidente de la Universidad de La Plata. Los rasgos que privilegia en su alocución son los de "delegados de la ciencia americana" (93) y "guías de la civilización moderna" (92), esa condición moderna a la cual buscaba adscribir los propósitos educacionales de la universidad argentina.

En otro discurso, motivado por la visita de Guillermo Ferrero a la Universidad Nacional de La Plata en 1907, ocasión en la que se le otorgó al historiador italiano el título de doctor honoris causa, el elogio al sujeto individual deviene en una reflexión epistemológica e institucional sobre el lugar de la Historia -y las Humanidades, en general- en la universidad platense. González se lamenta en su discurso de que todavía no existía en esa Universidad "el instituto especial de ciencias históricas y literarias, que no tardará, sin duda, en tomar forma en medio de sus escuelas, y en el cual Ferrero sería recibido como en dominio propio [...]" (99)4.

${ }^{4}$ En otro de los discursos compilados en este libro, ya se habla de la Sección de Filosofía, Historia y Letras de la Universidad de La Plata, sección que, efectivamente, 
En el mismo discurso, el sujeto celebrado se constituye en una sinécdoque de una entidad mayor, porque en su persona se cifra -siempre a juicio de González- la representación de la cultura italiana, cuyo peso en la conformación de la intelectualidad argentina moderna el orador considera indubitable. En la figura de Ferri, González rinde "homenaje a las universidades de Italia" (104) y destaca

... la deuda de reconocimiento que la cultura argentina tiene con las universidades de Italia, que desde hace medio siglo nos envían sus profesores en las ciencias y en las letras, para ponernos en contacto con la alta cultura humana (...) y han concurrido a crear esa íntima comunicación del espíritu del pueblo italiano con el nuestro, hasta compenetrarnos con los más caros ideales y presentar hoy el caso verdadero, y quizás único, de dos nacionalidades distantes y distintas, situadas en continentes diversos, unidas por una amistad y una asimilación tan profundas, que superan a las convenciones y a los estímulos artificiales de la política.

(...) la vida italiana debe ser estudiada y considerada como un problema propio, entre los varios que constituyen el cosmopolitismo particular de la República Argentina (101).

Estos comentarios se complementan con el elogio de la "sangre ancestral, de puro origen latino" que alimenta "el ancho río de nuestra futura raza" (102).

También en otro discurso, de 1908, pronunciado para homenajear a Enrique Ferri en la Universidad Nacional de La Plata, González menciona "la gloriosa Italia, amada de los argentinos" (107). En todos los casos, la conformación del sujeto cuya actividad profesional se distingue, está basada en rasgos intelectuales y morales, es decir, que se trata de una etopeya ${ }^{5}$. Los

se constituyó en 1909. Respecto de esta cuestión, que involucra el problema de la institucionalización de las disciplinas universitarias en la Argentina, Carlos Altamirano y Beatriz Sarlo señalan que "Si hasta entonces las facultades de Derecho y Medicina eran también los canales por excelencia de acceso a la vida intelectual y cultural, hacia el 900 se comienza a percibir su inadecuación e insuficiencia” (Altamirano y Sarlo, 1997: 169).

${ }^{5}$ Entendemos la etopeya en el sentido clásico, retórico, del término, como esa figura de pensamiento que consiste en la descripción de cualidades morales, conductas, 
rasgos genéricos mediante los que se diseña esa etopeya permiten, como en el caso de Ferrero mencionado antes, convertir a Ferri en representante de un colectivo mayor, los "miembros honorarios europeos" de esa Universidad, "por cuyo intermedio ella se vincula con la ciencia madre de nuestra civilización" (107). De ese modo, Ferri es ubicado "entre los civilizadores" (108), una caracterización que será compartida por otro visitante ilustre, esta vez, español: el escritor y político Vicente Blasco Ibáñez.

En efecto, uno de los discursos incluidos en Política espiritual tuvo como objetivo presentar al novelista Blasco Ibáñez en el teatro Odeón de Buenos Aires, donde el visitante inició una serie de conferencias, el 12 de junio de 1909. La proximidad del Centenario -ya explicitada en la dedicatoria del libro-, así como de la reconciliación con España, signada por los eventos posteriores al año 98 del siglo anterior y por la resignificación de los vínculos con la península, producto de las corrientes inmigratorias a la Argentina, deja su impronta en un discurso claramente influenciado por lo que David Viñas denominó el “tópico optimista e integrador” de esa fecha conmemorativa (1964: 340). Ello explica que González reciba a Blasco Ibáñez como "primer heraldo de la jubilosa reconciliación espiritual y afectiva de 1910" (112). En este caso, además, la identificación cultural tiene una ventaja extra - si se la compara con el caso italiano antes mencionado- que es el idiomático. Por eso, el elogio a Blasco Ibáñez deviene en una sutil autofiguración, cuando González lo homenajea como artista y escritor, aprovechando el gesto para inscribirse a sí mismo, especularmente, en el discurso:

Venir un escritor de idioma castellano en nuestra patria, a saludar a Blasco Ibáñez en este acto, en que va a hacerse oír en el habla materna de Sud América, se me figura uno de nuestros ríos, turbios y tortuosos por el limo que traen disuelto y el impulso desordenado de sus aguas, corriendo a echarse en el seno del mar, transparente y majestuoso, con la depuración y el sedimento de los siglos (115).

vicios, virtudes, en definitiva, de aspectos no físicos de la descripción de un sujeto. En este punto, la etopeya se diferencia de la prosopografía, basada en los caracteres físicos, y del retrato, aunque eventualmente la etopeya puede formar parte de este último (Garavelli, 1988: 272; Miraux, 2005: 49). 
Sabemos, efectivamente, que ambos escritores, Blasco y González, se escribían desde la publicación de Mis montañas en 1893, lo cual esclarece la vinculación personal y literaria entre el orador y el sujeto celebrado en su alocución, más allá de las cuestiones políticas o académicas circunstanciales ${ }^{6}$. Pero la alabanza al "novelista moderno" no se queda en el ámbito de lo estrictamente literario, por el contrario, se destaca en él su cualidad de "observador" del orden social, de "experimentador" y, sobre todo, la de ser un "educador supremo" (116). La cuestión lingüística también aparecerá en uno de los discursos en homenaje a Rafael Altamira, quien es presentado como el "conductor casi exclusivo en lengua castellana de las ideas modernas de enseñanza histórica” (140).

La condición magisterial es, como hemos podido apreciar hasta aquí, clave de bóveda en la construcción de estos elogios de González a distintas personalidades. Uno de los motivos más claros de eso es que muchos de los discursos fueron pronunciados en el ámbito académico, pero también se explica por el énfasis asignado por González a la educación como parte de un proyecto político, algo sobre lo cual volveremos más adelante. La celebración de la figura del maestro como rol social ejemplar, reaparece en otro de los discursos, nuevamente en homenaje a Rafael Altamira, para inaugurar el curso de "Metodología de la Historia", a cargo de este último, en julio de 19097 . Otra vez se habla de la "ciencia europea, representada por un maestro ilustre" (121), a quien se alude como "el ilustre profesor de Oviedo" (122) y se repite el tópico del profesor europeo que llega como maestro a América:

... la serena y experimentada enseñanza de un maestro que condensa en sí, aparte de su propia ciencia, la ciencia acumulada en labor secular

\footnotetext{
${ }^{6}$ Recordemos que Vicente Blasco Ibáñez había viajado a la Argentina en 1909, por primera vez, estimulado por el ingeniero Emilio Mitre, director de La Nación de Buenos Aires, donde el escritor valenciano se desempeñaba como corresponsal político desde 1905. Entre ese año de 1909 y 1914, Blasco Ibáñez realizó cinco viajes a la Argentina y brindó más de cien conferencias de difusión de temas hispánicos, en Buenos Aires, en otras ciudades del interior del país y en países limítrofes (Scarano, 2000: 69-ss).

${ }^{7}$ Aunque incluido en la segunda parte del libro, este discurso es, por su fecha, históricamente anterior al discurso sobre Altamira que ya mencionamos, ubicado en la parte primera de Política espiritual.
} 
por los viejos institutos europeos, en los cuales la ciencia antigua, como los vinos centenarios, se condensa y se bebe en una gota que guarda y resume el espíritu de los siglos (124).

De este modo, la relación entre Altamira y la Universidad de La Plata se amplía, mediante una serie de círculos concéntricos, hasta convertirse en una relación entre la ciencia y la universidad europea y sus contrapartes argentinas. La imagen convocada es, podría decirse, la metáfora básica de la paternidad y la herencia: "Sea, pues, bienvenido en el seno de la universidad más joven de América, el representante de la magna ciencia docente de Europa” (125), imagen que se profundiza con la del maestro ejemplar, al advertir que tanto los maestros como los alumnos platenses serán "discípulos" de Altamira (126).

El profesor de Oviedo es, tal parece, una de las figuras más frecuentadas en Política espiritual, pues un tercer discurso, fechado el 9 de octubre del mismo año, le está destinado. En esa ocasión, Altamira recibía el título de doctor honoris causa y en la pieza oratoria compuesta para la ocasión González introdujo la cita a uno de los autores más recurrentes en su pensamiento sobre materia educativa, al afirmar que "Altamira, como Ruskin, ha absorbido en el huerto cerrado de la ciencia esa vocación evangélica de la educación” $(138)^{8}$. La mención a John Ruskin es, en efecto, frecuente en Política espiritual. González cita como referencia sobre cuestiones educativas el libro del autor británico Corona de oliva silvestre, del cual cita en traducción al español un pasaje en el que se define la educación como "una labor penosa, continua, difícil, que debe ejecutarse por la bondad, la diligencia, el entusiasmo, el precepto y el estímulo, pero más que todo por el ejemplo" (80) ${ }^{9}$. Es interesante notar que esas frases, tomadas de una

${ }^{8}$ Es comprensible que el célebre crítico de arte y educador británico John Ruskin (1819-1900) haya alcanzado un papel significativo en el pensamiento educativo de Joaquín González, si se tiene en cuenta que ambos coincidían en la necesidad de modernizar sus países mediante un moderado reformismo social y la ampliación de la educación a la clase trabajadora, por cuyo acceso a los museos e instituciones educativas Ruskin batallaba en el Reino Unido.

${ }^{9}$ Entendemos que González está citando la traducción del siguiente fragmento de Ruskin: "Education (...) It is a painful, continual, and difficult work; to be done by kindness, by watching, by warning, by precept, and by praise, -but above all- by example" (Ruskin, 1882: 157-158). 
conferencia brindada por Ruskin en 1869, se encuentran en un párrafo que se inicia con esta afirmación, de la cual podemos apreciar los ecos en el proyecto político y educacional de González: "Educate, or govern, they are one and the same word" (Ruskin, 1882: 157).

En la referencia a la "vocación evangélica" de Altamira, así como en otros pasajes, aparece la imagen del educador como una suerte de sacerdote secular. En esa misma línea, se encuentra en estos discursos una serie de vocablos de evidentes connotaciones religiosas, empleados para describir a las personas o las acciones de estos educadores o "embajadores intelectuales". Se observa, en consecuencia, la trasposición del léxico religioso que permite diseñar la imagen magisterial como la de un sacerdote en un mundo secular, cuando González describe

... la misión de Altamira en América: me refiero a la enseñanza objetiva del ejemplo, en un medio en el cual esos casos de consagración son desconocidos. Sus conferencias, lecciones y consejos orales podrán acaso perderse en parte de la memoria de sus oyentes; pero nunca se perderá la influencia directa, el recuerdo de esta magna tarea desempeñada por un maestro sin desfallecimientos, sin quejas, sin inútiles intermitencias, sin asperezas, sin vanidades y sin ostentaciones; de esta prueba viviente de la enorme potencialidad productiva del esfuerzo disciplinado y nutrido de amplia preparación anterior; de esta palabra serena, sabia, elegante y ungida de un cierto perfume místico, de este misticismo afectivo que nace de las almas delicadas, que se consagran a una vocación definitiva e ideal (140-141. Las cursivas son nuestras) ${ }^{10}$.

\footnotetext{
${ }^{10}$ Acerca de la percepción epocal de cómo el léxico religioso se estaba trasladando a esferas secularizadas, como la ciencia o la educación, encontramos un interesante comentario en la sección de "Análisis de libros y revistas" del primer volumen de la Revista de Filosofía, dirigida por José Ingenieros. Allí se reproducen pasajes de un escrito de Juan Chiabra, publicado inicialmente en la Revista Argentina de Ciencias Políticas y en el cual su autor defendía la necesidad de establecer Facultades de ciencias de la educación. Un fragmento de ese escrito pone al desnudo la transposición léxica de lo sagrado a lo profano que comentamos: "No basta robar algunas palabras a la antigua religión; no basta decir religión del deber, religión civil, apostolado, misión, sacrificio, martirio, fe política. Es menester despertar, en la educación científica popular, aquel sentimiento de rectitud que es incorruptible en el fondo del hombre, especialmente del pueblo, y que ahora se halla ofuscado por prejuicios, decepciones, amarguras, miserias, ejemplos tristes que vienen de lo alto" (VVAA, 1915: 172).
} 
El discurso retoma, a su vez, la identificación del hombre -Altamiracon la institución -la Universidad de Oviedo- y la patria -España- tal como puede apreciarse en frases como las siguientes: "este pergamino [el diploma del doctorado honoris causa] es un símbolo para nosotros muy querido, -el de un amor sincero de esta patria nuestra por su augusta y noble madre España, y de un sentimiento nuevo de fraternal afecto por la escuela de Oviedo" (142).

Esta misma sección segunda del libro, titulada "Embajadores intelectuales”, se cierra con un discurso muy interesante que González pronunció en carácter de Ministro de Justicia e Instrucción Pública, en junio de 1905 -es decir, el discurso más antiguo de todos los que aparecen en el libro. El tema fue la presentación de un actor, Mr. Coquelin, en la clase de idioma francés de la Escuela Normal de Profesorado en Lenguas Vivas de la ciudad de Buenos Aires. Arte dramático, cultivo del idioma -en este caso, francésy educación femenina ${ }^{11}$ son las columnas sobre las cuales se estructura el elogio al "gran actor señor Coquelin" (145), de quien se dice que "puede reclamar para sí el honor de haber hecho amar el idioma y admirar el genio intelectual de su patria en todos los países que ha visitado" (146).

La tercera y última parte de Política espiritual, la sección "En la tribuna pública y parlamentaria”, ofrece menos ejemplos de estos discursos laudatorios de personalidades, aunque significativos. Uno de ellos es un discurso pronunciado en un acto de la sociedad de Beneficencia de La Plata, el 9 de julio de 1907, en el cual se entregaban "premios a la virtud”. En él, afirmaba:

... Aquí estoy (...) en el instante en el cual se tributa el premio inefable del reconocimiento y de la justicia, a los héroes, tanto más grandes cuanto más modestos, de esa lucha silenciosa del trabajo y de la práctica de las virtudes esenciales a la existencia, dignidad y perpetuación de la familia humana (151).

${ }^{11}$ Explícitamente, el discurso hace mención a sus alocutarios, "las jóvenes de nuestras escuelas normales de profesoras" (145), ofreciendo un claro indicador sobre el predominio femenino en la composición del cuerpo estudiantil en instituciones como el Profesorado de Lenguas Vivas. 
Esta noción de heroísmo no es ajena, como podemos apreciar, al diseño de las figuras magisteriales que ya comentamos, una heroicidad propia de los tiempos modernos y de la especialización de los roles y saberes en la sociedad. Quizá una de las formas de ese heroísmo secular, moderno y modesto, como el que González celebraba ante la Sociedad de Beneficencia, sea el que se constituye en la descripción profesional y moral de la señorita maestra Máxima Lagos, en un discurso que nuestro autor pronunció en nombre de las asociaciones de profesores y del personal docente de las escuelas públicas, en ocasión de la jubilación de "la noble dama" (218), el 31 de diciembre de 1909. En esa ocasión, González destacaba la necesidad de "premiar una vida de labor, de consagración y de virtud" (218) con una "recompensa moral" (221) y, en la misma vertiente retórica de los otros discursos, comunicaba a su auditorio que

... La recompensa de las vidas consagradas a un deber, a una misión, a un propósito honesto y superior, es una honda y prolífica lección de moral; porque, así como el precio de la cosecha o el pago del trabajo renuevan las energías del agricultor o del obrero, así la sanción social o pública del bien moral realizado, multiplica las fuerzas del espíritu y las dispone para las acciones más elevadas, esas que enaltecen la persona y dignifican la raza humana (218).

En este caso, en que se realiza una suerte de balance de la vida profesional de Máxima Lagos, se pone en evidencia un recurso que, de un modo u otro, está presente en varios de estos escritos: la reducción de la trayectoria vital al desempeño profesional, de la vida a la obra, como puede verse en pasajes como los que siguen:

Una mirada retrospectiva sobre la vida de la querida maestra de nuestros hijos, que ahora recibe su premio definitivo de honor y de reposo, revela que el secreto de su éxito y de su victoria fue el amor de los niños -amor de hermana, de madre y de compañera-, que daba calor e impulso siempre renovados a su corazón y a su inteligencia, y vencía con espontaneidades y recursos inexhaustos, las inevitables rutinas de una tarea sin cesar repetida (218).

Huelga decir que esta operatoria de selección de la trayectoria del sujeto homenajeado no circunscribe su función al elogio retórico: también impli- 
ca una consecuencia de orden pragmático, pues se propone como ejemplo a imitar, es decir, como modelo de conductas y modos de acción. En el caso de la señorita Lagos, ese propósito se enuncia claramente cuando la felicita por "su ejemplar consagración a la escuela durante tres décadas en forma y con caracteres tales que la erigen en un modelo, en un tipo superior de maestra, cuya imitación significaría un progreso colectivo para la enseñanza nacional" (221).

Luego de haber repasado los tópicos presentes en varios de los discursos reunidos en Política espiritual, podemos sistematizar algunas conclusiones, provisorias pero que podrían ser fructíferas para orientar indagaciones de mayor profundidad en otras zonas de la producción del escritor riojano.

En primer lugar, parece evidente la vinculación de este tipo de discursos, celebratorios de individualidades en las cuales se destaca una trayectoria vital dominada por el cultivo de la tarea intelectual, con ciertos aspectos de la escritura biográfica. Y nos referimos, puntualmente, a la funcionalidad sociocultural de la biografía que, sobre todo en la época que nos ocupa, era un género "por definición edificante y moralizador, al servicio de una estrategia de socialización destinada a colectivos amplios” (Hernández Sandoica, 2005: 24-25). En estos casos, no es la biografía en tanto registro de una experiencia vital múltiple y compleja lo que se rescata, sino una faceta de esa trayectoria existencial: la académica, científica o educacional. Es decir, que sobre la trama de la vida de los sujetos elogiados, se recorta un modelo o patrón que se ofrece a los lectores como guía a seguir. La escritura biográfica de este tipo, que reduce la historia de una vida a la concreción de una obra -ya sea una obra literaria, científica o educacional-, lleva "implícito un sistema completo de valores formativos (no es el menor aquel de la perseverancia), un catálogo de virtudes que define e informa la ambición del carácter, su forja controlada desde la infancia y hacia la juventud" (Hernández Sandoica, 2005: 25). En ese sentido, los discursos de González pueden integrarse en un corpus textual mayor, orientado a la constitución de modelos modernos de heroicización de personajes de existencia histórica, pautados por tópicos como la vocación innata, la unidad interior y el triunfo de las prácticas civilizatorias sobre rasgos de barbarie, ignorancia o animalidad (Barreto de Souza, 2001: 218).

Pero además, dentro de las múltiples formas de la escritura biográfica, 
estos discursos exhiben una cercanía particular con el tipo discursivo del elogio fúnebre, descontando, desde luego, el carácter luctuoso de este último. Sobre todo porque pueden entenderse como una suerte de balance de una trayectoria, como queda ilustrado ejemplarmente en el caso de la jubilación de la maestra Máxima Lagos, así como por el recurso a la emoción o afecto del auditorio en relación con el sujeto objeto del discurso -despedidas entre colegas, homenajes de discípulos a maestros, etc. Algunos rasgos del homenaje fúnebre son, efectivamente, compartidos por los discursos que analizamos aquí, sobre todo aquellos rasgos propios de las necrologías de personajes públicos. Por empezar, la idea de que "toda ceremonia fúnebre es sobre todo una puesta en forma simbólica de un discurso sobre los vivos, dirigiéndose únicamente a los vivos” (Dulong, 1994: 629). Algo similar podría predicarse de estos textos, dado el carácter ejemplar que se confiere a los sujetos que son el objeto de estos discursos. Por ejemplo, es obvio que la funcionalidad de destacar las virtudes pedagógicas de Máxima Lagos no apunta solamente a elogiar su tarea, ya concluida, como maestra, sino también a ofrecer un modelo de conducta para los y las docentes todavía en ejercicio. Del mismo modo, ponderar la buena dicción de Monsieur Coquelin no responde solamente a un ejercicio de la cortesía: se pretende, indudablemente, que las alumnas del Instituto de Lenguas Vivas emulen a ese "príncipe de la dicción" en su dominio de la lengua francesa. En todos los casos, no se trata pura y exclusivamente de aquilatar los méritos de una individualidad, sino de exhibir los atributos del titular de un rol -el profesor, la maestra, el actor, el historiador, etc.-, atributos que pasan a convertirse en modélicos para ese mismo rol.

Por otro lado, es inevitable pensar cómo, al convertirse en el orador autorizado, elegido o convocado para pronunciar estos discursos, Joaquín González se instala en el lugar de un político e intelectual que todavía exhibe rasgos del letrado tradicional, debido a cierto carácter disciplinariamente inespecífico y un afán totalizador - puede hablar de enseñanza del francés, de ciencia o de historiografía, por ejemplo- así como a su relación estrecha con la gestión cultural desde el Estado que, si bien tributaria de sus cargos públicos, se ampara parcialmente en su prestigio como escritor ${ }^{12}$.

${ }^{12}$ Para pensar la articulación entre proyecto escriturario de Joaquín V. González y su función pública, ha sido muy útil Chein (2007), especialmente 61-ss. 
En síntesis, en el campo intelectual argentino del Centenario, Joaquín González legitima su propio rol como guía de una política cultural y educativa moderna, mediante el recurso a las piezas oratorias centradas en el elogio de sujetos modélicos. El retrato ideal de quien se considera, en cada caso, como primus inter pares, habilita la enunciación de un discurso eunómico (Dulong, 1994: 634), en el cual la circunstancia académica o profesional que le da origen se ve sobrepasada al convertirse en pretexto para el diseño de los roles necesarios para el buen funcionamiento social, así como de los atributos conferidos a cada uno de esos roles. En estos discursos, que textualizan una autointerpretación de la cultura argentina, se ven entramadas una perspectiva intelectual, múltiples codificaciones retóricas y necesidades sociohistóricas que, siempre a juicio de González, exigen la formulación de una Política espiritual.

\section{Referencias}

Altamirano, C. y Sarlo, B. (1997). La Argentina del Centenario: campo intelectual, vida literaria y temas ideológicos. En Ensayos argentinos. De Sarmiento a la vanguardia. Segunda edición (pp. 161-199). Buenos Aires: Ariel.

Barreto de Souza, A. (2001). Caxias na memória biográfica. A construção de uma heroicidade moderna. Varia Historia, 24, 210-227.

Chein, D. J. (2007). La invención literaria del folklore. Joaquín V. González y la otra modernidad. Primera edición. San Miguel de Tucumán: Edición de autor.

Dalmaroni, M. (2006). Una república de las letras. Lugones, Rojas, Payró. Escritores argentinos y Estado. Primera edición. Rosario: Beatriz Viterbo.

Dulong, D. (1994). Mourir en politique. Le discours politique des éloges funèbres. Revue française de science politique, XLIV, 4, 629-646.

Estrella Gutiérrez, F. (1969). Joaquín V. González, escritor [1963]. En Estudios literarios (pp. 151-175). Primera edición. Buenos Aires: Academia Argentina de Letras.

Garavelli, B. M. (1988). Manual de retórica. Primera edición. Madrid: Cátedra. González, Joaquín V. (1935). Política espiritual en Obras completas de Joaquín V. González. Volumen XV (pp. 6-222). Segunda edición. Buenos Aires: Universidad Nacional de La Plata.

Hernández Sandoica, E. (2005). La biografía, entre el valor ejemplar y la experiencia vivida. Asclepio, LVII, 1, 23-41.

Lotman, I. M. (1996). La semiosfera. I. Semiótica de la cultura y del texto. Selección y traducción del ruso por D. Navarro. Madrid: Frónesis, Cátedra, Universidad de Valencia. 
Luna, F. (dir.). (2001). Joaquín V. González. Primera edición. Buenos Aires: Planeta.

Marasso, A. (1946). Joaquín V. González. Primera edición. Buenos Aires: Emecé editores.

Miraux, J-P. (2005). La autobiografía: las escrituras del yo. Traducción de H. Cardoso. Primera edición. Buenos Aires: Nueva Visión.

Ruskin, J. (1882). The future of England (Delivered at the R. A. Institution, Woolwich, December 14, 1869). En The works of John Ruskin, Honorary Student of Christchurch, and Honorary Fellow of Corpus Christi College, Oxford. Volume VI. The Crown of Wild Olive. Kent, George Allen. Disponible en http://www.archive.org

Scarano, M. E. (2000). Desde la otra orilla del Atlántico: Utopía y ficción en Vicente Blasco Ibáñez. En J. Oleza y J. Lluch (eds.), Vicente Blasco Ibáñez: 1898-1998. La vuelta al siglo de un novelista. Actas del Congreso Internacional celebrado en Valencia del 23 al 27 de noviembre de 1998 (pp. 67-91). Volumen I. Primera edición. Valencia: Biblioteca Valenciana / Generalitat Valenciana, Conselleria de Cultura i Educació, Direcció General del Libre i Coordinació Bibliotecária.

Viñas, D. (1964). Literatura argentina y realidad política. Buenos Aires: Jorge Álvarez.

VVAA. (1915). Análisis de libros y revistas. Revista de Filosofía, I/1, 148-173. 